\title{
Study of Straw Chamber Lifetime with Argon Ethane*
}

\author{
R. Mir \\ University of Washington, Seanle, WA 98195
}

\author{
J. Adler, T. Bolion, K. Bunnell, E. Cheul, C. Grab2, G. Maraheri A. Odian, \\ D. Pitman, W. Stockhausen ${ }^{3}$, W. Toki, W. Wadley, C Wood \\ Stanford Linear Accelerator Center, Stanford, CA 9430:
}

\begin{abstract}
We present detailed laboratory measurements of the lifetime of a small test chamber. simulating the Mark III straw vertex chamber conditions. The tests were carried out with in argon ethane 50/50 gas mixture at 3 atmospheres :bsolute pressure and $3.9 \mathrm{kV}$ was applied to the wires. After the accumulation $c=0.02$ $\mathrm{C} / \mathrm{cm}$ on a single straw continuous discharges began. The addition of alc hol or water yapor to the gas mixture was found to extend the iifetime of the raws. Continuous flow of the gas mixture with water vapor through the straws pro.snged the lifetime significantly. We present preliminary results on the effects of changing the gas mixture inside the straws at regular time intervals. Adding a small percentage of water vapor to the argon-ethane gas and flowing the gas mixture in the straws can improve the liferime by more than an order of magnitude. An accumulated charge of $1.0 \mathrm{C} / \mathrm{cm}$ on a single straw has been obtained.
\end{abstract}

\section{Introduction}

Wire chamber ageing is important in experiments which are exposed to high fluxes of particles. Ageing manifests itself by spontaneous current and rate increase after exposure to radiation. The gas amplification decreases and spontaneous discharges may begin.

\section{Experimental}

We have measured the lifetime of a prototype straw chamber under various operating conditions. The test apparatus (Figure 1) consists of four straws in a pressurized vessel. The straws are $12 \mathrm{~cm}$ long, $0.8 \mathrm{~cm}$ in diameter, and are constructed of aluminized Mylar. A gold-plated

* Work supported in part by the Department of Energy, under contracts DE-AC0376SF00515, and by the National Science Foundation.

Presented at the 5th International Wire Chamber Conference, Vienna, Austria, February 13-17, 1989. 
tungsten sense wire is centered in each straw. The wire is $50 \mu \mathrm{m}$ in diameter and is tensioned to $275 \mathrm{~g}$. The raw materials are the same as those used in the Mark III vertex chamber ${ }^{5}$ ( $\mathrm{VC}$ ). in most of the tests the straws were surrounded by an $8 \mathrm{mCi}$ Fe55 source, spotted on a thin copper sheet, which uniformly irradiates each straw over a length of $10 \mathrm{~cm}$. Data were taken at 3 atmospheres absolute pressure 6 and a high voltage of $3.9 \mathrm{kV}$ was applied to the sense wires. In these tests the gas mixture was Matheson brand argon-ethane 50/50. The gas flowed through electro-polished stainless steel pipes and over a reservoir containing the additive to be tested (water or alcohol). The temperature of the reservoir and the concentration of the additive $(0.2 \%$ water vapor, $0.4 \%$ alcohol) were controlled by a temperature stabilized water bath?

Throughout each test the gas volume inside the straws was either a) kept constant; b) allowed to flow continuously; or c) replaced at different but regular time intervals.

\section{Results and discussion}

Twenty five tests were performed. Typical test conditions had a singles rate of $-100 \mathrm{kHz}$ per wire and a current of $-5 \mu \mathrm{A}$ per wire as the initial conditions. The pulse height was $15-20 \mathrm{mV}$ in a $50 \Omega$ load.The straw lifetime, measured in deposited charge per unit length $[\mathrm{C} / \mathrm{cm}]$, was calculated from the initiation of each test to the point when the current and singles rate began to escalate (Figure 2 shows a measurement of the current).

The first set of measurements compare the straw lifetimes for various additives. The gas volume was kept constant throughout each test. The results of these tests are shown in Figure 3. The error bars represent a $10 \%$ systematic error on the time when the currents and singles rate began to escalate.

In another set of tests the gas mixture flowed continuously through the straws. When water vapor was added to the gas mixture the lifetime improved significantly. After a month of constant irradiation each straw had accumulated $1.03 \mathrm{C} / \mathrm{cm}$ with no indication of perfornance deterioration, at which point the measurement was stopped.

The Mark III VC was designed to allow a moderate gas flow through the straws. However, one can speed the gas exchange by replacing the gas volume in the chamber every few hours. This condition was simulated in the test chamber by replacing the gas volume at constant time intervals. A volume change every 5 minutes in the test chamber corresponds to a volume change every 23 hours in the VC, under typical VC operating conditions. Preliminary results of these tests are shown in Figure 4. The error bars represent a $10 \%$ systematic error on the time when the currents and singles rate began to escalate. The measurements with 3 to 6 minutes between volume changes show fluctuations, due to argon ethane gas mixture changes (up to $1 \%$ ). We plan to repeat these measurements with a high radintion source $(\mathrm{BO} \mathrm{mCi}$ ) to speed up the tests. 
To conclude, the lifetime without gas circulation or the addition of water vapor uas measured to be $-0.02 \mathrm{C} / \mathrm{cm}$. The addition of $0.2 \%$ of water vapor or alcohol extended the lifetime by $-50 \%$. Continuous flow of the gas mixture through the straws further prolonged the lifetime. With the addition of $0.2 \%$ water vapor and continuous flow of the gas mixture through the straws a lower limit of $-1.0 \mathrm{C} / \mathrm{cm}$ for the lifetime was obtained. Replacing the gas mixure in the straws at constant intervals was found to extend the lifetime. The shorter the interval between gas volume replacernents, the longer the lifetime became. This is of practical consequence for the Mark III VC, and should be taken into consideration for future designs.

\title{
References
}

[1] Present address: Comell University, Ithaca, NY 14853.

[2] Present address: CERN, EP, 1211 Geneva 23, Switzerland.

[3] Present address: Bayer AG, Leverkusen, D-5090 Bayerwerk, W. Germany.

[4] Present address: University of Wyoming, Laramie, WY 82070.

[5] J. Adler et al, SLAC-PUB-4578, Aug 1988, accepted for publication by NIM.

[6] Regulated by an Edwards Datametrics Controller 1501 and Barocel Pressure Sensor S90A-100P-2Q8-V1X-4D.

[7] Cole Parmer Bath 730-13R, Immersion Circulator Model 1266-02, T.C. Probe D83679 YS1410.

\section{DLSCLAIMRR}

\begin{abstract}
This report was prepared as an wcooust of wotk sponsored by an apency of the Unitod States Govemneat. Neither the United Slates Government nor any asency thereot, not any of their employes makes any warranty, exprus or implied, or eseumes any lezal ljability or responsj. bility for the sceuracy. completentals, of usefulness of any information, appajatus, product, of process disclowed, or reptevents that its use would not infringe privalely owned rishts. Refer. ence herein to any specific commercial product. process, or service by trade name, Irademark. manufacturer, of ofherwise does not mecessurily constitute or imply its endorsement, recommendatiun, of lavoring by the Uniled States Government of any agency thereof. The view and opinions of authors expressed herein do not necessarily stale or refiect those of the Uniled States Gowernment or any agency theteot
\end{abstract}




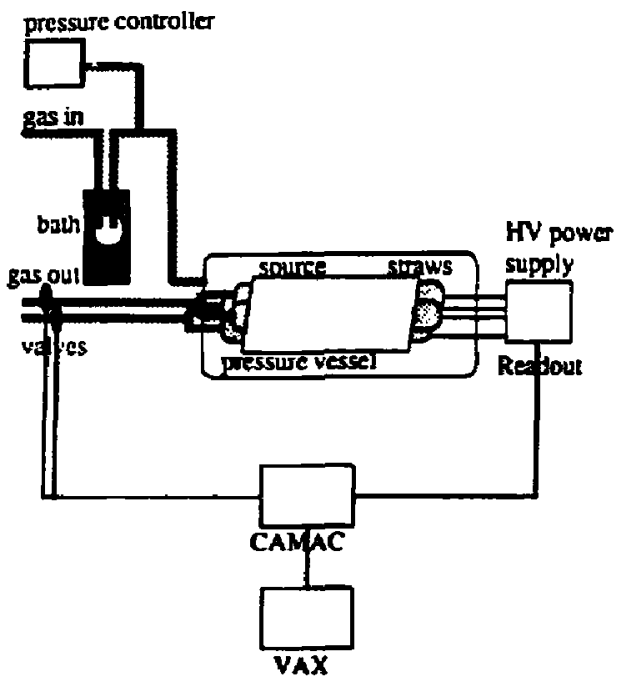

Figure 1: The experimental setup.

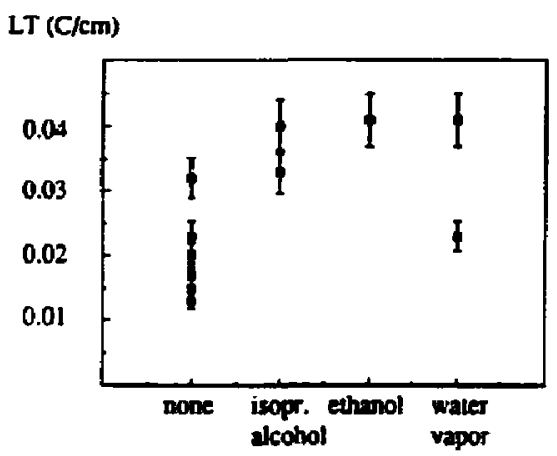

Additive

Fig 3: Lifetime as a function of additives to the agon-ethane $(50 / 50)$ gas mixture. The gas mixture was not circulated.

\section{Current ( $\mu \mathrm{A})$}

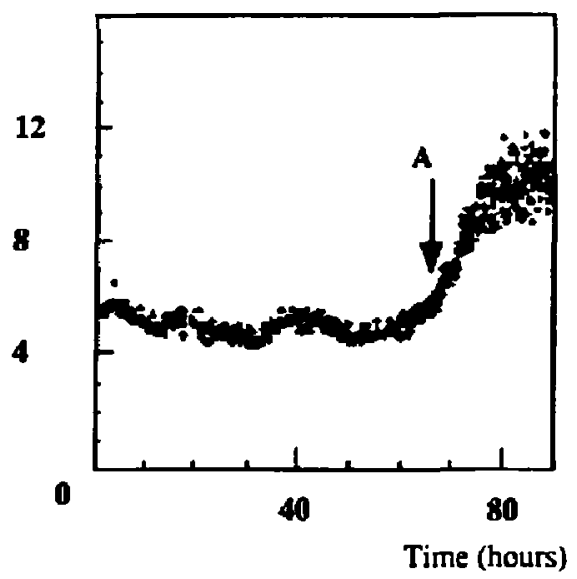

Figure 2: Current as a function of time, for a typical test. In point $\mathbf{A}$ the current begins to escalate.

LT $(\mathrm{C} / \mathrm{cm})$

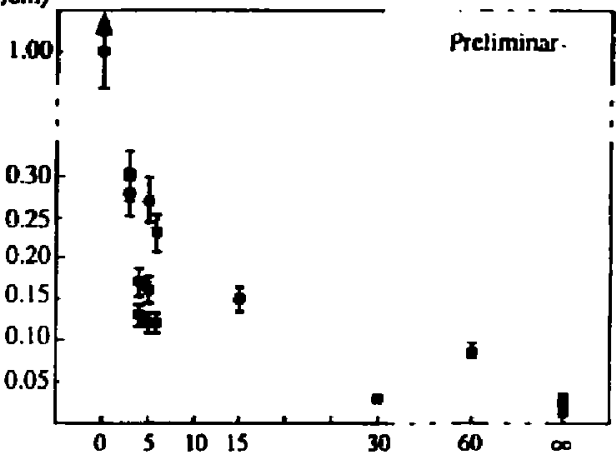

interval between volume changes (minutes)

Fig 4: Lifetime as a function of the rate of volume changes (water vapor added). 